\title{
Prevalence and Comorbidities of Attention Deficit Hyperactivity Disorder Among Adults and Children/Adolescents in Korea
}

\author{
Jeong-Cheol Seo ${ }^{1}$, Duk-In Jon ${ }^{2}$, Se-Hoon Shim ${ }^{3}$, Hyung-Mo Sung ${ }^{4}$, Young Sup Woo ${ }^{5}$, Jeongwan Hong ${ }^{6}$, \\ Sung-Yong Park ${ }^{7}$, Jeong Seok Seo ${ }^{8}$, Won-Myong Bahk ${ }^{5}$ \\ ${ }^{1}$ Department of Psychiatry, School of Medicine, Konkuk University, Chungju, ${ }^{2}$ Department of Psychiatry, Hallym University Sacred Heart \\ Hospital, College of Medicine, Hallym University, Anyang, 'Department of Psychiatry, Soonchunhyang University Cheonan Hospital, \\ Soonchunhyang University, Cheonan, ${ }^{4}$ Department of Psychiatry, Soonchunhyang University Gumi Hospital, Soonchunhyang University, Gumi, \\ ${ }^{5}$ Department of Psychiatry, College of Medicine, The Catholic University of Korea, Seoul, ${ }^{6}$ Department of Psychiatry, Iksan Hospital, Iksan, \\ ${ }^{7}$ Department of Psychiatry, Keyo Hospital, Uiwang, ${ }^{8}$ Department of Psychiatry, Chung-Ang University Hospital, College of Medicine, Chung-Ang \\ University, Seoul, Korea
}

Objective: This study investigated the prevalence and comorbidities of attention deficit hyperactivity disorder (ADHD) among adults and children/adolescents in Korea.

Methods: This study used data from the Korea Health Insurance Review and Assessment Service collected from 2008 to 2018. Study participants comprised patients with at least one diagnosis of ADHD (International Statistical Classification of Diseases and Related Health Provisions, 10th revision code F90.0). Prevalence rates and psychiatric comorbidities were also analyzed.

Results: We identified 878,996 patients diagnosed with ADHD between 2008 and 2018. The overall prevalence rate of diagnosed ADHD increased steeply from 127.1/100,000 in 2008 to 192.9/100,000 in 2018; it increased 1.47 times in children/adolescents ( $\leq 18$ years) and 10.1 times in adults ( $>18$ years) during this period. Among adult and children/adolescent ADHD patients, 61.84\% (95\% confidence interval [95\% Cl] 61.74-61.93) and 78.72\% $(95 \% \mathrm{Cl} 78.53-$ 78.91) had at least one psychiatric comorbidity, respectively.

Conclusion: Our results showed that the prevalence rate of diagnosed ADHD has increased in Korea; however, it is lower than the global average. Further studies are required to identify and treat vulnerable populations appropriately.

KEY WORDS: Attention deficit hyperactivity disorder; Prevalence; Comorbidity.

\section{INTRODUCTION}

Attention deficit hyperactivity disorder (ADHD) is the most common neurobehavioral disorder in childhood,

Received: December 8, 2020 / Revised: March 12, 2021

Accepted: March 26, 2021

Address for correspondence: Jeong Seok Seo

Department of Psychiatry, Chung-Ang University Hospital,

College of Medicine, Chung-Ang University, 102 Heukseok-ro,

Dongjak-gu, Seoul 06973, Korea

E-mail: sjs52632@hanmail.net

ORCID: https://orcid.org/0000-0002-4880-3684

Won-Myong Bahk

Department of Psychiatry, Yeouido St. Mary's Hospital, College of

Medicine, The Catholic University of Korea, 10 63-ro,

Yeongdeungpo-gu, Seoul 07345, Korea

E-mail:wmbahk@catholic.ac.kr

ORCID: https://orcid.org/0000-0002-0156-2510

Two corresponding authors contributed equally in this research. characterized by inattention, impulsivity, and hyperactivity [1]. Despite ADHD being considered a disabling and common disorder that occurs only in childhood, recent research suggests that it persists into adulthood in 30$70 \%$ of cases [2-4]. Although controversial, some researchers have paradigmatically assumed that adult-onset ADHD is a distinct entity [5-7].

Since the diagnostic criteria for ADHD changed in the Diagnostic and Statistical Manual of Mental Disorders-5 published in 2013, the focus has shifted to include the recognition and management of the condition for all ages [8]. ADHD recognition appears to be increasing; higher rates of diagnosis and treatment in recent years and an increase in ADHD prescriptions over time have been observed across all genders and age groups [9]. In Korea, since September 2016, insurance benefits have been

(c) This is an Open-Access article distributed under the terms of the Creative Commons Attribution Non-Commercial License (http://creativecommons.org/licenses/by-nc/4.0) which permits unrestricted non-commercial use, distribution, and reproduction in any medium, provided the original work is properly cited. 
granted to adult patients with ADHD who were first diagnosed between the ages of 6 and 65 years.

However, prevailing misunderstandings and prejudice regarding ADHD prevent optimal diagnosis and treatment [10]. Previous studies have found that ADHD is associated with a high rate of psychiatric comorbidities, which complicate the clinical manifestation of the disorder [11]. Concerns regarding overdiagnosis and psychostimulant abuse persist [12]. For these reasons, patients with ADHD may still be underdiagnosed and undertreated, and the rates of treatment discontinuation are higher than expected considering the persistence of the disorder [13].

It has been reported that ADHD causes substantial financial burden; familial issues such as parenting stress, marital discord, and parental depression; and negative effects on self-esteem, social relationships, and workplace performance $[14,15]$. If treated early and optimally, the trajectory of poor psychiatric outcomes could be potentially altered, and the emergence of psychiatric comorbidities can be prevented [16].

Many studies have been conducted in the past decades to better understand the etiology of ADHD, using a variety of approaches, including behavioral, neurophysiologic, and genetic [17-20]. Although epidemiological data and evidence from clinical practice are essential for proper diagnosis and determining treatment strategies, nationwide epidemiological data on ADHD across all age groups in the Korean population are scarce.

We classified adults and children/adolescents based on whether they were above or below 18 years, regardless of past ADHD diagnoses. This study investigated the prevalence and comorbidities of ADHD among adults and children/adolescents in Korea using data from the National Health Insurance Database that were collected from 2008 to 2018

\section{METHODS}

\section{Data Source and Participants}

This study used data collected by the Korea Health Insurance Review and Assessment Service (HIRA) from January 1, 2008, to December 31, 2018. The HIRA is a government agency supervised by the Korean Ministry of Health and Welfare. It examines and evaluates the medical expenses of all citizens (approximately 50 million) covered by the Korean National Health Insurance (approximately 97\% of the population) and Medical Aid (approximately 3\%) [21]. The HIRA database contains information pertaining to individual beneficiaries, including healthcare services, such as diagnoses, procedures, and prescriptions.

ADHD diagnosis is confirmed as per the International Statistical Classification of Diseases and Related Health Provisions, 10th revision (ICD-10). Study participants comprised patients with at least one diagnosis of ADHD (ICD10 code F90.0) in both inpatient and outpatient settings between January 1, 2008, and December 31, 2018.

\section{Measures}

The annual prevalence of ADHD was calculated as the number of people who were diagnosed with ADHD per year (2008 - 2018) divided by the total population as per the National Statistical Office records.

For analyzing psychiatric comorbidities, we identified the main diagnostic codes and six sub-diagnostic codes among patients with ADHD. Psychiatric diagnoses were stratified according to the ICD-10 classification as follows: substance use disorder (F10 to F19), schizophrenia spectrum disorder and other psychotic disorders (F20 to F29), depressive disorder (F32 and F33), bipolar disorder (F30 and F31), anxiety disorder (F40 and F41), obsessive-compulsive disorder (F42), post-traumatic stress disorder (F43), somatic symptom disorder (F45), eating disorder (F50), sleep disorder (F51), intellectual disability (F70 to F79), communication disorder (F80), specific learning disorder (F81), autism spectrum disorder (F84), tic disorder (F95), and oppositional defiant disorder/conduct disorder (F91 and F92).

Information on demographic and sociological variables was obtained and classified as follows. Age was classified into two groups: children/adolescents ( $\leq 18$ years) and adults ( $>18$ years). The types of insurance were divided into two categories: national health insurance and medical aid. Clinicians' specialties were categorized as psychiatry and others. Hospital level was classified into two groups: general hospitals and primary care clinics.

\section{Statistical Analysis}

The HIRA database consists of five tables presenting general characteristics, health services, diagnosis information, outpatient prescriptions, and healthcare service provider information. All tables were merged using the 
key ID, and ADHD prevalence and comorbidities were measured using the merged table. Depending on the characteristics of the data, these were compared using an independent $t$ test or chi-square test. The trends in the prev-

Table 1. Demographic characteristics of patients with diagnosed ADHD between 2008 and 2018

\begin{tabular}{lc}
\multicolumn{1}{c}{ Variable } & Number $(\%)$ \\
\hline Total & 878,996 \\
Age $(\mathrm{yr})$ & \\
$0-6$ (preschool) & $74,963(7.95)$ \\
$7-12$ (school) & $441,690(46.87)$ \\
$13-18$ (adolescent) & $302,480(32.10)$ \\
$19-30$ (young adult) & $81,789(8.68)$ \\
$\geq 31$ (adult) & $41,476(4.40)$ \\
Sex & \\
Male & $674,154(76.70)$ \\
Female & $204,842(23.30)$ \\
Health insurance & \\
National health insurance & $811,534(91.80)$ \\
Medical aid & $72,214(8.17)$ \\
Others & $310(0.04)$ \\
Medical institution type & \\
General hospital & $300,797(31.18)$ \\
Primary care clinic & $663,864(68.82)$ \\
Physician specialty & $782,622(77.21)$ \\
Psychiatry & $230,963(22.79)$ \\
Non-psychiatry &
\end{tabular}

ADHD, attention-deficit/hyperactivity disorder. alence of diagnosed ADHD from 2008 to 2018 were examined using Poisson regression. All statistical analyses were performed using the SAS statistical application program (release 9.3; SAS Institute Inc., Cary, NC, USA). The significance level was set at $p<0.05$.

The study protocol was approved by the Konkuk University Institutional Review Board (IRB No. $\mathrm{KUCH}$ 2017-08-023).

\section{RESULTS}

We identified 878,996 patients diagnosed with ADHD between 2008 and 2018. The demographic and sociological characteristics of the participants are presented in Table 1. The majority of the diagnosed patients were male $(76.7 \%)$, between $7-12$ years $(46.87 \%)$, had national health insurance $(91.80 \%)$ and were treated in a primary care clinic $(68.82 \%)$ by psychiatrists $(77.21 \%)$.

\section{Prevalence of Diagnosed ADHD}

The prevalence trends of diagnosed ADHD are shown in Table 2 and Figure 1. The overall prevalence rates of diagnosed ADHD increased steeply from 127.1/100,000 in 2008 to $192.9 / 100,000$ in 2018 (trends over time using Poisson regression, beta $=1.0243, p<0.001$ ).

Table 2. Trends in the prevalence of diagnosed ADHD between 2008 and 2018

\begin{tabular}{|c|c|c|c|c|c|c|c|c|c|c|c|c|c|}
\hline \multirow{2}{*}{$\begin{array}{l}\text { Age } \\
\text { group }\end{array}$} & \multirow{2}{*}{ Sex } & \multicolumn{11}{|c|}{ Prevalence of diagnosed ADHD per 100,000} & \multirow{2}{*}{$\begin{array}{c}\begin{array}{c}\text { Poisson } \\
\text { regression }\end{array} \\
\text { Estimate } \\
(95 \% \mathrm{Cl})\end{array}$} \\
\hline & & 2008 & 2009 & 2010 & 2011 & 2012 & 2013 & 2014 & 2015 & 2016 & 2017 & 2018 & \\
\hline \multirow[t]{3}{*}{ All } & Both & 127.1 & 139.7 & 146.4 & 159.4 & 173.5 & 164.1 & 150.9 & 148.0 & 153.4 & 166.9 & 192.9 & $\begin{array}{c}1.024 \\
(1.024-1.025)\end{array}$ \\
\hline & Male & 198.5 & 217.9 & 228.4 & 246.7 & 266.6 & 252.6 & 233.1 & 227.2 & 234.6 & 252.2 & 283.5 & $\begin{array}{c}1.019 \\
(1.018-1.020)\end{array}$ \\
\hline & Female & 55.4 & 61.2 & 64.1 & 71.8 & 80.2 & 75.4 & 68.6 & 68.9 & 72.3 & 81.9 & 102.6 & $\begin{array}{c}1.042 \\
(1.040-1.043)\end{array}$ \\
\hline \multirow{3}{*}{$\begin{array}{l}\text { Child and } \\
\text { adolescent } \\
(\leq 18 \mathrm{yr})\end{array}$} & Both & 533.3 & 593.7 & 641.4 & 701.9 & 773.4 & 734.5 & 674.8 & 647.2 & 661.7 & 702.5 & 783.4 & $\begin{array}{c}1.023 \\
(1.022-1.023)\end{array}$ \\
\hline & Male & 804.9 & 898.4 & 969.5 & $1,058.3$ & $1,161.0$ & $1,107.9$ & $1,024.7$ & 985.2 & $1,009.5$ & $1,071.7$ & $1,180.4$ & $\begin{array}{c}1.023 \\
(1.022-1.023)\end{array}$ \\
\hline & Female & 233.3 & 258.6 & 281.6 & 312.5 & 352.0 & 330.7 & 298.1 & 284.5 & 289.1 & 307.9 & 360.1 & $\begin{array}{c}1.024 \\
(1.022-1.025)\end{array}$ \\
\hline \multirow[t]{3}{*}{$\begin{array}{l}\text { Adult } \\
\qquad(>18 \mathrm{yr})\end{array}$} & Both & 7.1 & 9.4 & 10.5 & 16.3 & 19.5 & 23.0 & 26.1 & 33.3 & 40.8 & 52.7 & 71.9 & $\begin{array}{c}1.248 \\
(1.246-1.251)\end{array}$ \\
\hline & Male & 8.3 & 11.0 & 13.3 & 21.0 & 25.2 & 30.8 & 35.9 & 45.2 & 55.5 & 70.0 & 92.1 & $\begin{array}{c}1.264 \\
(1.251-1.257)\end{array}$ \\
\hline & Female & 6.0 & 7.9 & 7.7 & 11.7 & 13.9 & 15.3 & 16.4 & 21.5 & 26.3 & 35.7 & 51.9 & $\begin{array}{c}1.238 \\
(1.234-1.242)\end{array}$ \\
\hline
\end{tabular}

ADHD, attention-deficit/hyperactivity disorder; $95 \% \mathrm{Cl}, 95 \%$ confidence interval. 
After stratifying by sex, we found that the prevalence rates in males had increased from 198.5/100,000 in 2008 to $283.5 / 100,000$ in 2018 (beta $=1.0191, p<0.001$ ), and that in females had increased from 55.4/100,000 in 2008 to $102.6 / 100,000$ in 2008 (beta $=1.0416, p<$
0.001). Although the annual prevalence rates were consistently higher among males than in females, the annual percentage change in prevalence rates was greater for females than for males.

After classifying by age group, we found that the preva-
All ADHD

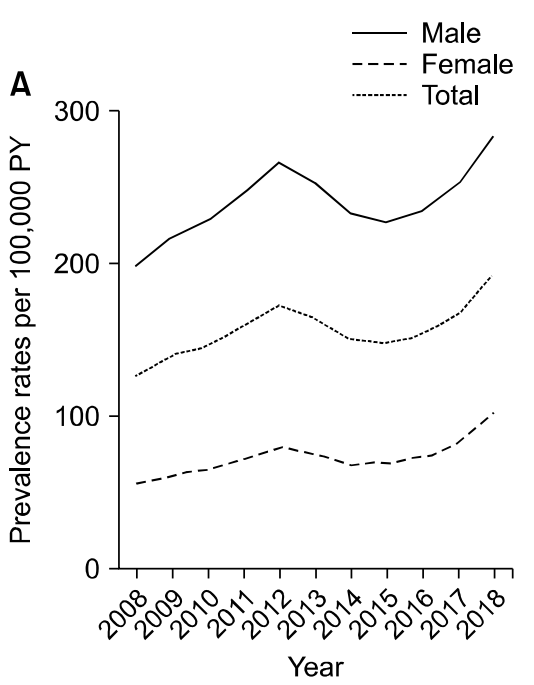

Child-adolescent $(\leq 18)$

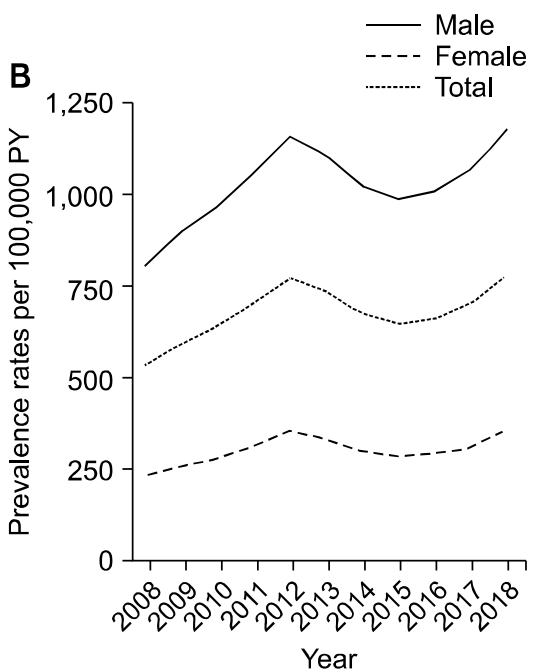

Adult $(>18)$

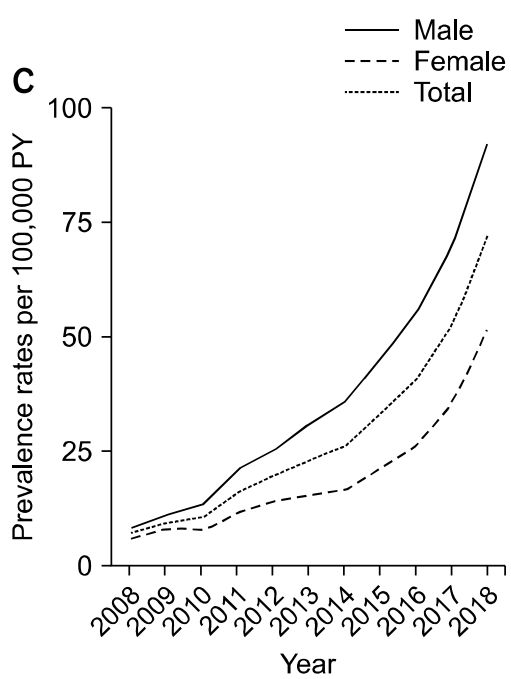

Fig. 1. Trends in the prevalence rates of diagnosed ADHD of (A) total patient, (B) child/adolescentpatient, (C) adult. ADHD, attention-deficit/hyperactivity disorder.

Table 3. Prevalence and odds ratios of psychiatric comorbidities in child/adolescent (age $\leq 18 \mathrm{yr}$ ) with ADHD and adult (age $>18 \mathrm{yr}$ ) with ADHD

\begin{tabular}{|c|c|c|c|c|c|}
\hline \multirow{2}{*}{ Psychiatric comorbidities } & \multicolumn{2}{|c|}{ Child/adolescent $(\leq 18 \mathrm{yr}$ ) } & \multicolumn{2}{|c|}{ Adult $(>18 \mathrm{yr})$} & \multirow{2}{*}{$\begin{array}{c}\text { Odds ratio } \\
(\text { ref }=\text { child/adolescent })\end{array}$} \\
\hline & $\%$ & $(95 \% \mathrm{Cl})$ & $\%$ & $(95 \% \mathrm{Cl})$ & \\
\hline All psychiatric disorders & 61.84 & $(61.74-61.93)$ & $78.72^{\dagger}$ & $(78.53-78.91)$ & $2.24(2.21-2.27)^{*}$ \\
\hline Substance use disorder & 0.08 & $(0.07-0.08)$ & $2.43^{\dagger}$ & $(2.36-2.50)$ & $33.13(30.68-35.86)^{*}$ \\
\hline Schizophrenia spectrum disorder & 2.39 & $(2.36-2.42)$ & $7.34^{\dagger}$ & $(7.22-7.46)$ & $3.31(3.23-3.38)^{*}$ \\
\hline Depressive disorder & 18.06 & $(17.99-18.14)$ & $45.76^{\dagger}$ & $(45.52-45.99)$ & $3.64(3.60-3.68)^{*}$ \\
\hline Bipolar disorder & 5.86 & $(5.81-5.90)$ & $15.44^{\dagger}$ & $(15.27-15.61)$ & $2.89(2.85-2.94)^{*}$ \\
\hline Anxiety disorder & 9.94 & $(9.89-10.00)$ & $23.80^{\dagger}$ & $(23.60-24.00)$ & $2.75(2.71-2.78)^{*}$ \\
\hline Obsessive-compulsive disorder & 2.17 & $(2.14-2.20)$ & $5.14^{\dagger}$ & $(5.04-5.25)$ & $2.46(2.40-2.52)^{*}$ \\
\hline Post-traumatic stress disorder & 2.23 & $(2.30-2.36)$ & $4.35^{\dagger}$ & $(4.25-4.44)$ & $1.80(1.75-1.84)^{*}$ \\
\hline Somatic symptom disorder & 0.26 & $(0.25-0.27)$ & $1.10^{\dagger}$ & $(1.05-1.15)$ & $3.78(3.56-4.01) *$ \\
\hline Eating disorder & 0.08 & $(0.08-0.09)$ & $0.58^{\dagger}$ & $(0.56-0.63)$ & $5.52(5.03-6.05)^{*}$ \\
\hline Sleep disorder & 0.94 & $(0.92-0.96)$ & $13.43^{\dagger}$ & $(13.31-13.63)$ & $15.15(14.8-15.53)^{*}$ \\
\hline \multicolumn{6}{|l|}{ Neurodevelopmental disorders } \\
\hline Intellectual disability & $7.64^{\dagger}$ & $(7.59-7.69)$ & 6.62 & $(6.50-6.74)$ & $0.85(0.83-0.86)^{*}$ \\
\hline Communication disorder & $2.68^{\dagger}$ & $(2.65-2.71)$ & 0.35 & $(0.32-0.38)$ & $0.13(0.12-0.14)^{*}$ \\
\hline Specific learning disorder & $1.58^{\dagger}$ & $(1.56-1.61)$ & 0.32 & $(0.29-0.34)$ & $0.19(0.18-0.21)^{*}$ \\
\hline Autism spectrum disorder & $2.96^{\dagger}$ & $(2.90-3.03)$ & 1.18 & $(1.09-1.28)$ & $0.44(0.40-0.48)^{*}$ \\
\hline Tic disorder & $11.44^{\dagger}$ & $(11.38-11.51)$ & 4.84 & $(4.73-4.94)$ & $0.42(0.41-0.43)^{*}$ \\
\hline $\begin{array}{l}\text { Oppositional defiant } \\
\text { disorder/conduct disorder }\end{array}$ & $9.56^{\dagger}$ & $(9.50-9.62)$ & 3.72 & $(3.64-3.81)$ & $0.38(0.37-0.39) *$ \\
\hline
\end{tabular}

Adjustments were made for age, sex.

ADHD, attention-deficit/hyperactivity disorder; $95 \% \mathrm{Cl}, 95 \%$ confidence interval.

*Significant $p$ value $<0.001 ;{ }^{\dagger}$ Values are more frequent comorbid conditions. 
lence rates in children/adolescents had increased from $533.3 / 100,000$ in 2008 to $783.4 / 100,000$ in 2018 ( $\beta=$ $1.0227, p<0.001$ ), and that in adult patients had increased from $7.1 / 100,000$ in 2008 to $71.9 / 100,000$ in $2008(\beta=1.2481, p<0.001)$. Although the annual prevalence rates were consistently higher among children/adolescents than among adults, the annual percentage change in prevalence rates in adults was greater than that in children/adolescents.

\section{Comorbidities}

Among the children/adolescent ADHD patients, $61.84 \%$ (95\% confidence interval [95\% Cl] 61.74-61.93) had at least one psychiatric comorbidity (Table 3). The following specific psychiatric comorbidities were identified in the order of decreasing likelihood: depressive disorder (18.06\%; 95\% Cl 17.99-18.14), tic disorder (11.44\%; $95 \% \mathrm{Cl} 11.38-11.51)$, anxiety disorder $(9.94 \% ; 95 \% \mathrm{Cl}$ 9.89-10.00), oppositional defiant disorder/conduct disorder (9.56\%; 95\% Cl 9.50-9.62), intellectual disability (7.64\%; 95\% Cl 7.59-7.69), and bipolar disorder (5.86\%; 95\% Cl $5.81-5.90)$.

Among adult ADHD patients, $78.72 \%$ (95\% Cl $78.53-$ 78.91) had at least one psychiatric comorbidity. The following specific psychiatric comorbidities were found in the order of decreasing likelihood: depressive disorder $(45.76 \%$; $95 \% \mathrm{Cl} 45.52-45.99)$, anxiety disorder $(23.80 \%$; $95 \% \mathrm{Cl} 23.60-24.00)$, bipolar disorder $(15.44 \% ; 95 \% \mathrm{Cl}$ 15.27-15.61), sleep disorder $(13.43 \%$; $95 \% \mathrm{Cl} 13.31-$ 13.63), and schizophrenia spectrum disorder and other psychotic disorders (7.34\%; 95\% Cl 7.22-7.46). Relative to children/adolescents with ADHD, adults with ADHD had high odds ratios for most psychiatric comorbidities, but had low odds ratios for neurodevelopmental comorbidities (Fig. 2).

\section{DISCUSSION}

To the best of our knowledge, this is the first nationwide study to investigate the prevalence and comorbidities of diagnosed ADHD among adults and children/adolescents in Korea using nationally representative data collected between 2008 and 2018.

In our analysis, we found that ADHD prevalence rates had increased for children/adolescents over the past decade, from 533.3 in 2008 to 783.4 in 2018, resulting in a relative difference of 1.47 times during the 11 -year period. Subdivided by period, the prevalence of diagnosed ADHD in children/adolescents had increased from 2009 to 2012, decreased from 2013 to 2015, and again increased from 2016 onwards. This is inconsistent with the results of previous studies that have reported a continuous increase [22]. This discrepancy can be explained by a negative campaign for overdiagnosis and the changes made to the insurance claim process. In particular, since April 1, 2013, outpatient counseling in psychiatry without drug prescription can be claimed by the general health consultation (ICD Z code) instead of the psychiatric disease code (ICD F code). Subsequently, many patients and caregivers opted for the general health counseling (ICD Z code) to avoid the stigma surrounding psychological help-seeking behavior.

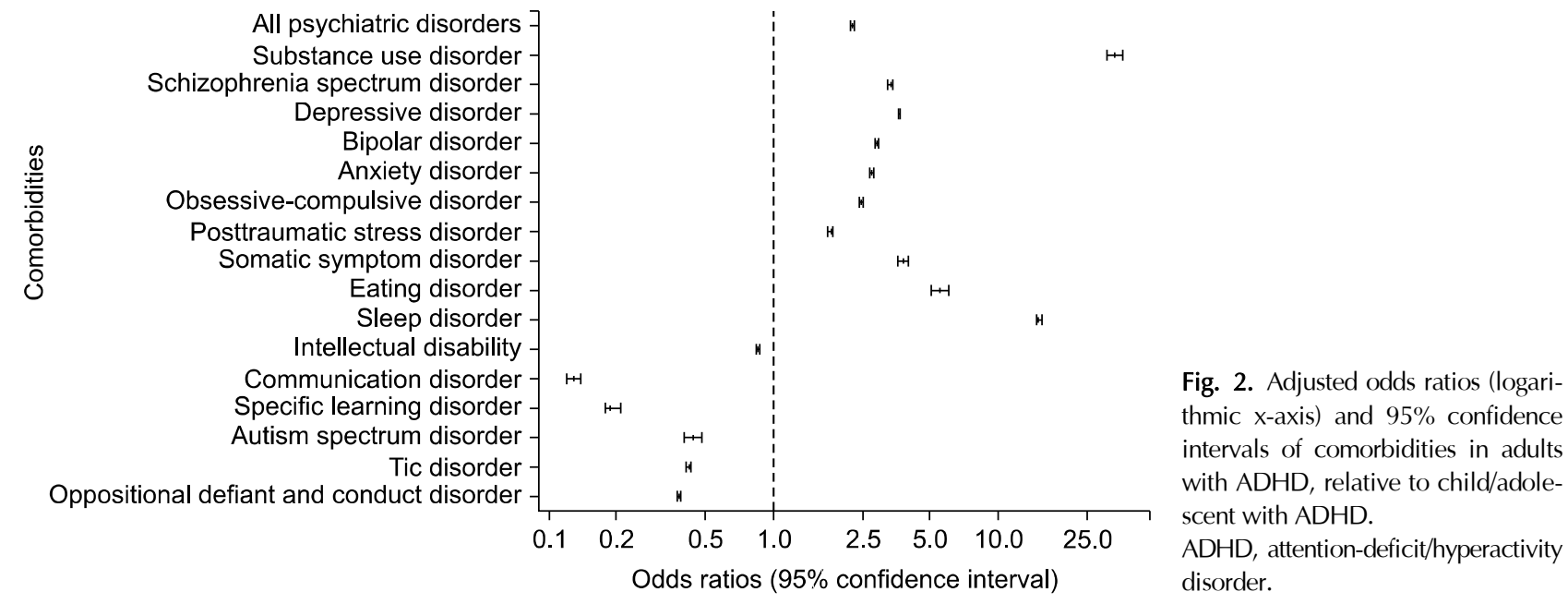


The prevalence rate has increased across all age groups over the past decade, especially in adults. We found that the prevalence of diagnosed ADHD in adults increased from 7.1 in 2008 to 71.9 in 2018 , resulting in a 10.1-fold difference during the 11-year period. Our results are consistent with published data, and similar increases have been reported worldwide. A recent study in the US found that the prevalence of ADHD among adults increased from $0.43 \%$ in 2007 to $0.96 \%$ in 2016 [9]. Another American study, using outpatient, inpatient, and pharmacy billing records, reported that the prevalence of ADHD diagnosis increased from 2.20/1,000 patients in 1999 to $10.57 / 1,000$ in 2010 [23]. In a German study, for the age group of 18 to 69 years, the frequency of diagnosis was $0.2 \%$ in 2009 and $0.4 \%$ in 2014 [24]. In a Swedish population-based study, the estimated annual prevalence of diagnosed ADHD increased from 0.58/1,000 persons in 2006 to 3.54/1,000 persons in 2011 [25].

There are multiple possible explanations for this trend that reflects an increase in the number of adults diagnosed with $A D H D$, such as the growing public awareness of $\mathrm{ADHD}$, increased awareness of the persistence of ADHD into adulthood, and increased recognition of adult ADHD symptoms by clinicians. This increasing trend could also be a result of changes made to the national health insurance coverage. In Korea, before August 2016, insurance benefits were granted only to patients who had been diagnosed with ADHD prior to the age of 12 years. After introducing the aforementioned changes, adults who were first diagnosed with ADHD between the ages of 6 and 65 years are now covered under the insurance benefits if the diagnostic criteria are met.

Although our findings report an increasing trend in the prevalence of adult ADHD and correspond with data reported in other studies, the numbers are lower than the global average, which may indicate under-diagnosis or under-treatment of ADHD in adults. Therefore, more effort must be invested in the diagnosis and treatment of ADHD among adults in Korea.

Our findings revealed that the prevalence of $\mathrm{ADHD}$ was higher in male patients than in female patients, which is consistent with findings of previous studies reporting that the male-to-female ratio ranges from 2:1 to 9:1 [26]. Women with ADHD were more likely to have internalizing problems and were significantly less likely to experience hyperactivity, inattention, and impulsivity, which can be attributed to gender differences [27].

Using data representing the national population, we investigated and compared psychiatric comorbidities in children/adolescents. This study confirmed that high psychiatric comorbidities exist in children/adolescents and adults with ADHD.

In ADHD patients, high rates of psychiatric comorbidities suggest that ADHD is a clinical group with different causes, risk factors, and outcomes rather than an independent clinical entity [28]. Some studies suggest that one disease increases the risk of developing another, or that comorbidities share genetic and environmental vulnerabilities [29,30]. Recently, considering the overlap of symptoms between ADHD and psychiatric comorbidities, it has been proposed that diagnosis and treatment should be approached using dimensional rather than categorical concepts [31].

Psychiatric comorbidities have a negative influence on diagnosis, prognosis, and treatment, causing clinically significant distress or impairment in social, academic, and occupational functioning [32]. Therefore, it is important to identify psychiatric comorbidities when treating ADHD [33]; subsequently, appropriate treatment strategies should be developed for the identified comorbidities.

In previous studies, reported rates of psychiatric comorbidities among children/adolescents with ADHD vary widely, but are generally reported to be within 50-90\%. In a study of 14,825 individuals with ADHD in Denmark, $52 \%$ of the children/adolescents with ADHD had at least one psychiatric comorbidity and $26 \%$ had two or more [34]. According to Yoshimasu et al. [35], 60\% of all children/adolescents with ADHD have at least one psychiatric comorbidity. A recent study found that the rate of psychiatric comorbidities among children/adolescents with ADHD is $92 \%$ [36]. Consistent with previous studies, we found that children/adolescents with ADHD exhibit a higher likelihood of experiencing psychiatric comorbidities.

In several studies, rates of psychiatric comorbidities among adults with ADHD are known to be higher than that of children/adolescents with ADHD. Findings from a Norwegian and German clinical study showed that as many as $80 \%$ of the adults with ADHD have at least one psychiatric comorbidity, such as depressive disorder, anxiety disorder, bipolar disorder, and substance use disorder [37,38]. According to Reinhold [39], 87\% of the adult $\mathrm{ADHD}$ patients have one or more psychiatric 
comorbidities.

Consistent with the findings of previous studies, we found a high comorbidity rate in adult patients with many different types of psychiatric disorders, including depressive disorder, anxiety disorder, bipolar disorder, and sleep disorder. However, the prevalence of substance use disorder, including alcohol use disorder, in adult ADHD patients was lower than that reported in previous studies. In an epidemiological study of alcohol use disorders (AUD) in the US, only $7.7 \%$ and $19.8 \%$ patients sought treatment annually and in their lifetime, respectively; additionally, only $3.6 \%$ received care from healthcare practitioners [40]. Since this study analyzed the use of medical institutions, it can be inferred that the low rate of AUD treatment was owing to it being a less prevalent comorbidity. Korea's strict legal restrictions on illegal and opioid drugs may have also contributed to substance use disorders being a less prevalent comorbidity in adult ADHD patients.

Previous studies have stated that psychotic disorders and ADHD are neurodevelopmental and have common comorbidities, which is consistent with the results of this study [41]. Several studies have reported that ADHD in children/adolescents is a risk factor for schizophrenia in adulthood, and ADHD and psychotic disorders share genetic and environmental risk factors $[42,43]$. Comorbidities between ADHD and psychotic disorders have important clinical significance, as the psycho-stimulant used in treating ADHD can worsen psychotic disorders [44]. Although the combination of psychostimulant and antipsychotics is controversial, there is some evidence that the careful use of psycho-stimulants is beneficial in treating ADHD when patients' psychotic symptoms are stabilized with antipsychotics $[41,45]$.

Although the rates of psychiatric comorbidities were similarly high in children/adolescents and adults with ADHD in our study, the psychiatric comorbidities differed in their prevalence. Neurodevelopmental disorders were more prevalent in children/adolescents with $\mathrm{ADHD}$, but mood disorders were more prevalent in adult ADHD patients, which is consistent with the findings in the existing literature.

Patients with ADHD and psychiatric comorbidities exhibit complex clinical characteristics, thereby making diagnosis difficult. Overlapping symptoms of ADHD and other psychiatric disorders may lead to misdiagnosis and inappropriate treatment [8]. If ADHD is not properly treat- ed, it can increase the risk of additional psychiatric disorders. In the course of treatment of ADHD patients, the higher the number of psychiatric comorbidities, the less effective the psychostimulant treatment is [46]. Depending on the age at which ADHD is first diagnosed, the patterns and rates of psychiatric comorbidities vary considerably; thus, it is important to evaluate and plan for treatment based on a clear understanding of this information. The recognition of comorbidities is of significance in both the academic and clinical contexts.

This study had some limitations. Since administrative claims data from inpatient and outpatient settings were used, the potential of referral bias should be considered in the interpretation of results. Because this was a cross-sectional study, we were unable to establish a causal relationship between ADHD and the reported comorbidities. It was not possible to distinguish between adult-onset ADHD and child-onset ADHD in the adult patient population. There was little information on individual characteristics such as race, ethnicity, socioeconomic status, and education level. Despite these methodological shortcomings, the present study has several advantages. Using data from the national health insurance system meant that this study included almost the entire Korean population, and as such is relatively more clinically representative.

This is the first study to identify key prevalence and comorbidity patterns of ADHD among adults and children/adolescents in Korea. Our results showed that the prevalence rate of diagnosed ADHD has increased in Korea, but is low compared to the global average. Our findings revealed high rates of psychiatric comorbidities in children/adolescents and adults with ADHD. In summary, we infer that a significant proportion of patients with ADHD remain either under-diagnosed or under-treated in Korea. Further studies are required to identify and appropriately treat vulnerable populations.

\section{Funding}

None.

\section{Acknowledgments}

All authors thank Professors Boram and Sunkyung for their valuable comments on statistical methods. 
Conflicts of Interest

No potential conflict of interest relevant to this article was reported.

\section{Author Contributions}

Conceptualization: Jeong Seok Seo, Won-Myong Bahk. Data acquisition: Jeong-Cheol Seo, Duk-In Jon, Se-Hoon Shim, Hyung-Mo Sung, Jeongwan Hong, Sung-Yong Park, Jeong Seok Seo, Won-Myong Bahk. Data analysis: Jeong-Cheol Seo, Young Sup Woo, Jeong Seok Seo, Won-Myong Bahk. Writing article: Jeong-Cheol Seo, Jeong Seok Seo. Intellectual comments and critics on the content: Duk-In Jon, Se-Hoon Shim, Hyung-Mo Sung, Young Sup Woo, Jeongwan Hong, Sung-Yong Park. All authors reviewed and approved for publication.

\section{- ORCID}

Jeong-Cheol Seo

Duk-In Jon

https://orcid.org/0000-0003-3239-2689

Se-Hoon Shim https://orcid.org/0000-0002-1565-7940

Hyung-Mo Sung https://orcid.org/0000-0002-3137-6591 Young Sup Woo https://orcid.org/0000-0002-2396-3358 Jeongwan Hong https://orcid.org/0000-0002-0961-838X https://orcid.org/0000-0003-0458-6750 Sung-Yong Park https://orcid.org/0000-0002-8685-620X Jeong Seok Seo https://orcid.org/0000-0002-4880-3684 Won-Myong Bahk https://orcid.org/0000-0002-0156-2510

\section{REFERENCES}

1. American Psychiatric Association. Diagnostic and statistical manual of mental disorders: DSM-5. 5th ed. Washington, D.C.:American Psychiatric Association;2013.

2. Barkley RA, Fischer M, Smallish L, Fletcher K. The persistence of attention-deficit/hyperactivity disorder into young adulthood as a function of reporting source and definition of disorder. J Abnorm Psychol 2002;111:279-289.

3. Turgay A, Goodman DW, Asherson P, Lasser RA, Babcock TF, Pucci ML, et al. Lifespan persistence of ADHD: the life transition model and its application. / Clin Psychiatry 2012;73:192-201.

4. Trollor JN. Attention deficit hyperactivity disorder in adults: conceptual and clinical issues. Med J Aust 1999;171:421-425.

5. Castellanos FX. Is adult-onset ADHD a distinct entity? Am J Psychiatry 2015;172:929-931.

6. Faraone SV, Biederman J. Can attention-deficit/hyperactivity disorder onset occur in adulthood? JAMA Psychiatry 2016;73: 655-656.

7. Sibley MH, Rohde LA, Swanson JM, Hechtman LT, Molina
BSG, Mitchell JT, et al. Late-onset $A D H D$ reconsidered with comprehensive repeated assessments between ages 10 and 25. Am J Psychiatry 2018;175:140-149.

8. Katzman MA, Bilkey TS, Chokka PR, Fallu A, Klassen LJ. Adult $A D H D$ and comorbid disorders: clinical implications of a dimensional approach. BMC Psychiatry 2017;17:302.

9. Chung W, Jiang SF, Paksarian D, Nikolaidis A, Castellanos FX, Merikangas KR, et al. Trends in the prevalence and incidence of attention-deficit/hyperactivity disorder among adults and children of different racial and ethnic groups. JAMA Netw Open 2019;2:e1914344.

10. Bruchmüller K, Margraf J, Schneider S. Is ADHD diagnosed in accord with diagnostic criteria? Overdiagnosis and influence of client gender on diagnosis. J Consult Clin Psychol 2012;80:128-138.

11. Cumyn L, French L, Hechtman L. Comorbidity in adults with attention-deficit hyperactivity disorder. Can I Psychiatry 2009;54:673-683.

12. Katzman MA, Bilkey T, Chokka PR, Fallu A, Klassen LJ. Re: Is adult attention-deficit hyperactivity disorder being overdiagnosed? Can J Psychiatry 2016;61:60-61.

13. Ginsberg Y, Quintero J, Anand E, Casillas M, Upadhyaya HP. Underdiagnosis of attention-deficit/hyperactivity disorder in adult patients: a review of the literature. Prim Care Companion CNS Disord 2014;16:PCC.13r01600.

14. Harpin VA. The effect of $A D H D$ on the life of an individual, their family, and community from preschool to adult life. Arch Dis Child 2005;90(Supp/ 1):i2-i7.

15. Biederman J. Attention-deficit/hyperactivity disorder: a life-span perspective. J Clin Psychiatry 1998;59 Supp/ 7:4-16.

16. Biederman J, Monuteaux MC, Spencer T, Wilens TE, Faraone SV. Do stimulants protect against psychiatric disorders in youth with ADHD? A 10-year follow-up study. Pediatrics 2009; 124:71-78.

17. Bobb AJ, Castellanos FX, Addington AM, Rapoport JL. Molecular genetic studies of ADHD: 1991 to 2004. Am J Med Genet Part B Neuropsychiatr Genet 2006;141B:551-565.

18. Shim SH, Kim YK, Hwangbo Y, Yoon HJ, Kim JS, Lee YJ, et al. The relationship between plasma erythropoietin levels and symptoms of attention deficit hyperactivity disorder. Clin Psychopharmacol Neurosci 2021;19:334-340.

19. Lee YJ, Jeong MY, Kim JH, Kim JS. Associations between the mismatch-negativity potential and symptom severity in medication-naïve children and adolescents with symptoms of attention deficit/hyperactivity disorder. Clin Psychopharmacol Neurosci 2020;18:249-260.

20. Kim SM, Min KJ, Han DH. Effects of methylphenidate on somatic symptoms and brain functional connectivity in adolescents with ADHD: a pilot study. Clin Psychopharmacol Neurosci 2021. http://www.cpn.or.kr/journal/view.html?uid= 1219\&vmd=Full. [Epub ahead of print]

21. Kim L, Kim JA, Kim S. A guide for the utilization of Health Insurance Review and Assessment Service national patient 
samples. Epidemiol Health 2014;36:e2014008.

22. Xu G, Strathearn L, Liu B, Yang B, Bao W. Twenty-year trends in diagnosed attention-deficit/hyperactivity disorder among US children and adolescents, 1997-2016. JAMA Netw Open 2018;1:e181471.

23. Zhu Y, Liu W, Li Y, Wang X, Winterstein AG. Prevalence of $A D H D$ in publicly insured adults. J Atten Disord 2018;22: 182-190.

24. Bachmann CJ, Philipsen A, Hoffmann F. ADHD in Germany: trends in diagnosis and pharmacotherapy. Dtsch Arztebl Int 2017;114:141-148.

25. Polyzoi M, Ahnemark E, Medin E, Ginsberg Y. Estimated prevalence and incidence of diagnosed ADHD and health care utilization in adults in Sweden - a longitudinal population-based register study. Neuropsychiatr Dis Treat 2018;14:1149-1161.

26. Huang $\mathrm{CL}$, Weng SF, $\mathrm{Ho} \mathrm{CH}$. Gender ratios of administrative prevalence and incidence of attention-deficit/hyperactivity disorder (ADHD) across the lifespan: a nationwide population-based study in Taiwan. Psychiatry Res 2016;244: 382-387.

27. Gershon J. A meta-analytic review of gender differences in ADHD. J Atten Disord 2002;5:143-154.

28. Biederman J, Newcorn J, Sprich S. Comorbidity of attention deficit hyperactivity disorder with conduct, depressive, anxiety, and other disorders. Am J Psychiatry 1991;148:564-577.

29. Rutter M. Isle of Wight revisited: twenty-five years of child psychiatric epidemiology. I Am Acad Child Adolesc Psychiatry 1989;28:633-653.

30. Kim KM, Kim JH, Kim D, Lim MH, Joo H, Yoo SJ, et al. Associations among high risk for sleep-disordered breathing, related risk factors, and attention deficit/hyperactivity symptoms in elementary school children. Clin Psychopharmacol Neurosci 2020;18:553-561.

31. Heidbreder R. ADHD symptomatology is best conceptualized as a spectrum: a dimensional versus unitary approach to diagnosis. Atten Defic Hyperact Disord 2015;7:249-269.

32. Kessler RC, Adler L, Barkley R, Biederman J, Conners CK, Demler $\mathrm{O}$, et al. The prevalence and correlates of adult $A D H D$ in the United States: results from the National Comorbidity Survey Replication. Am I Psychiatry 2006;163: 716-723.

33. Shim S, Woo YS, Kim JS, Heo IS, Yoon $\mathrm{H}$, Sung $\mathrm{H}$, et al. Comparison between atomoxetine and OROS methylphenidate as an adjunctive to SSRIs in attention-deficit/hyperactivity disorder adults with comorbid partially responsive major depressive disorder: a head-to-head, 12-week, randomized, rater-blinded clinical trial. Clin Psychopharmacol Neurosci 2021. http://www.cpn.or.kr/journal/view.html?uid= $1217 \& v m d=F u l l$. [Epub ahead of print]

34. Jensen CM, Steinhausen HC. Comorbid mental disorders in children and adolescents with attention-deficit/hyperactivity disorder in a large nationwide study. Atten Defic Hyperact Disord 2015;7:27-38.

35. Yoshimasu K, Barbaresi WJ, Colligan RC, Voigt RG, Killian JM, Weaver AL, et al. Childhood ADHD is strongly associated with a broad range of psychiatric disorders during adolescence: a population-based birth cohort study. I Child Psychol Psychiatry 2012;53:1036-1043.

36. Silva D, Houghton S, Hagemann E, Jacoby P, Jongeling B, Bower C. Child attention deficit hyperactive disorder co morbidities on family stress: effect of medication. Community Ment Health J 2015;51:347-353.

37. Torgersen T, Gjervan B, Rasmussen K. ADHD in adults: a study of clinical characteristics, impairment and comorbidity. Nord J Psychiatry 2006;60:38-43.

38. Sobanski E, Brüggemann D, Alm B, Kern S, Deschner M, Schubert T, et al. Psychiatric comorbidity and functional impairment in a clinically referred sample of adults with attention-deficithyperactivity disorder (ADHD). Eur Arch Psychiatry Clin Neurosci 2007;257:371-377.

39. Reinhold JA. Adult ADHD: a review of the clinical presentation, challenges, and treatment options. Psychiatr Times 2015;32:41.

40. Grant BF, Goldstein RB, Saha TD, Chou SP, Jung J, Zhang H, et al. Epidemiology of DSM-5 alcohol use disorder: results from the National Epidemiologic Survey on A/cohol and Related Conditions III. JAMA Psychiatry 2015;72:757-766.

41. Levy E, Traicu A, lyer S, Malla A, Joober R. Psychotic disorders comorbid with attention-deficit hyperactivity disorder: an important knowledge gap. Can I Psychiatry 2015;60(3 Suppl 2):S48-S52.

42. Dalsgaard S, Mortensen PB, Frydenberg M, Maibing CM, Nordentoft M, Thomsen PH. Association between AttentionDeficit Hyperactivity Disorder in childhood and schizophrenia later in adulthood. Eur Psychiatry 2014,29:259-263.

43. Owen MJ, O'Donovan MC. Schizophrenia and the neurodevelopmental continuum:evidence from genomics. World Psychiatry 2017;16:227-235.

44. Ekinci O, Sabuncuoglu O. Psychosis associated with switching from risperidone to aripiprazole in an adolescent on methy/phenidate treatment. Prog Neuropsychopharmacol Biol Psychiatry 2011;35:648-649.

45. Kooij SJ, Bejerot S, Blackwell A, Caci H, Casas-Brugué $M$, Carpentier PJ, et al. European consensus statement on diagnosis and treatment of adult $A D H D$ : The European Network Adult ADHD. BMC Psychiatry 2010;10:67.

46. Abikoff H, Klein RG. Attention-deficit hyperactivity and conduct disorder: comorbidity and implications for treatment. J Consult Clin Psychol 1992;60:881-892. 